\title{
Brain Arterio-Venous Malformations Presenting with Seizures and Diagnosed on CT Scan: A Case Report
}

\author{
Kiridi Ek (MBBS, MSC, FWACS) ${ }^{1,2,4}$, Dambo Nd (MBBS, MPH) ${ }^{3}$, Onyia Oi (MBBS) ${ }^{4}$ \\ ${ }^{1}$ Department of Radiology, Niger Delta University Teaching Hospital, Okolobiri, Bayelsa State \\ ${ }^{2}$ Silhouette Radio-diagnostic Consultants, Yenagoa, Bayelsa State \\ ${ }^{3}$ Directorate of Clinical Services, Hospitals Management Board, Yenagoa, Bayelsa State \\ ${ }^{4}$ Department of Internal Medicine, Federal Medical Centre, Yenagoa, Bayelsa State
}

\begin{abstract}
O I$ is a 35 year old male who was brought into the emergency department of the Federal Medical centre with the third episode of seizure in his life. The last seizure had occurred about a year prior to presentation and he had never presented for a medical consult. A CT scan done showed features of extensive left hemispheric brain arterio-venous malformation.
\end{abstract}

\section{Introduction}

Arterio-venous malformations (AVM) of vessels within the brain are rare occurring in less than $1 \%$ of the general population $(1,2)$. While it is accepted to be a rare condition, poor access to diagnostic resources(3) may mean that even the few cases that present may not be diagnosed. Identified case reports from Nigeria have been from the University College, $\operatorname{Ibadan}(1,3,4)$ and a special mention to the case series by Odeku (4) who in 1968 described 19 intracranial vascular anomalies identified over a four year period with 3 of those being arterio-venous malformations.

While AVM's of the brain are thought to be congenital in origin and may even have a familial component(5), several authors have demonstrated de novo development of AVM's in children and adults(2,6). Elevated levels of vascular endothelial growth factor (VEGF) have been implicated in the pathogenesis of AVM's. Other considerations are that a trigger (mechanical, hormonal, thrombotic, hemodynamic, thermal, ischemic/hypoxemic, or inflammatory in nature) could act on susceptible vascular cellular elements leading to the development of an AVM (6).

Common presenting symptoms include headaches, neurological deficits and seizures. Other modes of presentation include intracranial haemorrhages, subarachnoid haemorrhages, trigeminal neuralgia, hydrocephalus and polycythemia $(1,3,7)$.

Imaging options that will lead to a diagnosis include a computed tomography (CT) scan, magnetic resonance imaging (MRI) and angiography(1,2,6). Digital subtraction angiography (DSA) is considered to be the gold standard for imaging in this condition (3).

We present the case report of an AVM diagnosed by CT scan.

\section{Case Report}

OI is a 35 year old male who was brought into the emergency department of Federal Medical Centre, Yenagoa, Bayelsa State with a history of intermittent generalised tonic clonic seizures which had begun 30 minutes prior to presentation and loss of consciousness of similar duration. Five episodes of seizures had been recorded in the intervening period. There was trauma to the head, face and right lower limb which resulted from a fall following the first episode of seizures. He's reported to have become incontinent of urine during the episodes but not of faeces. He had not missed any meals preceding the onset of seizure, no prior history of head injury or aura.

He had suffered a seizure at a younger age (informant could not provide the age) and another about a year prior to this episode. There was no report of neuroimaging as he had not been taken to the hospital following these episodes. Information regarding his birth could not be provided. He was not a known diabetic or hypertensive and was not on any form of medication. There was no family history of seizure disorders. He took alcohol socially, did not use tobacco or recreational drugs.

On examination, he was unconscious with a Glasgow Coma Scale (GCS) score of 3/15. There was periorbital haematoma surrounding the left eye. There were also bruises on his left shoulder and knee. He was afebrile $\left(36.8^{0} \mathrm{C}\right)$, not pale, well hydrated, anicteric, not cyanosed and had no pedal oedema. His pupils were equal, central and reactive to light. There were no features suggestive of meningism or cranial nerve deficit. There was a global reduction in the tone and power of the limbs.

The pulse was 84 beats per minute and the blood pressure was $140 / 80 \mathrm{mmHg}$. The jugular venous pressure was not elevated and the apex beat was located at the 5LICS, MCL. Only the first and second heart sounds were heard.

The respiratory rate was 18 cycles per minute and the breath sounds were vesicular in all the lung fields. 


\section{International Journal of Science and Research (IJSR) \\ ISSN (Online): 2319-7064 \\ Index Copernicus Value (2015): 78.96 | Impact Factor (2015): 6.391}

His abdomen was full and moved with respiration. It was soft and no organs or masses were palpated.

A diagnosis of status epilepticus was made.

The results of the random blood sugar, full blood count, serum electrolyte, urea and creatinine were within the normal range. The urinalysis done showed no abnormality. The electroencephalogram result was normal. The brain CT scan done showed an arterio-venous malformation in the brain.

During his review, he started having a seizure and he was placed in the left lateral position and thereafter, he was given intravenous diazepam $10 \mathrm{mg}$ stat. He did not have any other seizures following this. He was also placed on intravenous $20 \%$ mannitol, $250 \mathrm{mls} 12$ hourly for 24 hours. He received carbamazepine tablets $200 \mathrm{mg} 12$ hourly and the physiotherapists were invited. He regained consciousness about an hour following admission. The neurosurgeon was invited to take over his care when the brain CT result was made available and he has been counselled on the options of management.

Axial slices on the CT scan showed brilliantly enhancing tubular serpinginous vessels with Hounsfield units ranging between 40 and 50, in the left temporal, parietal, frontal and occipital cortices of the brain. (Pictures 2,4, 5\& 6). The transverse, straight and cavernous sinuses were dilated (Pictures 3 \& 5). There were multiple punctuate calcifications in the parietal lobe(Pictures $1 \& 5$ ). The lateral and third ventricles were dilated and the fourth ventricle was compressed resulting in a non-communicating hydrocephalus (Picture 4). A midline shift to the right was noted (Picture $1 \& 2$ ). There was no evidence of intra-cranial bleeding or hematoma.
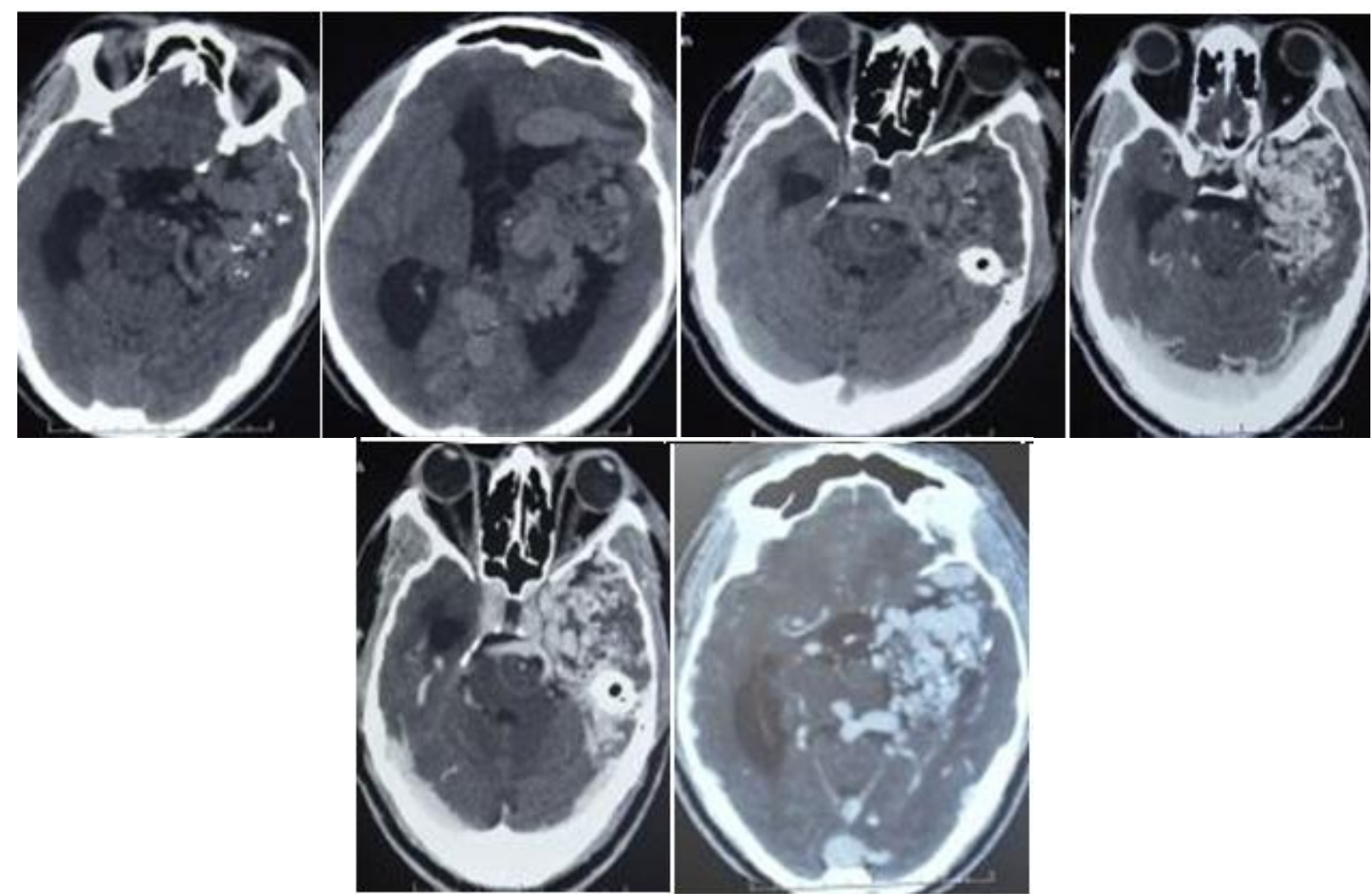

Top row: Pictures 1-3 (left to right): shows isodense tubular structures in the left cerebral hemisphere. Note multiple calcifications within the tubular structures as well as dilatation of the lateral and $3^{\text {rd }}$ ventricles.

Bottom row: Pictures 4-6 (left to right): shows marked enhancement of the tubular structures

\section{Discussion}

AVM's consist of vascular clusters that form direct arteriovenous shunts without any intermediary capillary network $(3,8)$. Criteria for making a diagnosis of AVM's on CT and MRI have been described $(9,10)$ but AdenijiSofolowe and Adeleye (3) have highlighted criteria for making the diagnosis of an AVM on CT scan in a resource poor setting such as ours. Features to be looked out for include, patchy areas of increased densities ranging from 50 to $100+$ Hounsfield Units (HU) interspersed with areas of low density, sometimes with calcifications, or it may sometimes be normal on pre-contrast CT. Immediately after a bolus injection of contrast agent, CT will show serpiginous dilated afferent and efferent vessels, as well as enhancement of the nidus of the AVM in more than $90 \%$ of cases with both intravascular and extra vascular accumulation of contrast within the malformation. These features were noted in the index patient.

When AVM's are encountered during neuroimgaing, other differentials including large developmental venous anomalies, malignant dural arterio-venous fistulas and Moyamoya disease need to be ruled out(11) because of the 


\section{International Journal of Science and Research (IJSR) \\ ISSN (Online): 2319-7064 \\ Index Copernicus Value (2015): 78.96 | Impact Factor (2015): 6.391}

differences in management options. These were ruled out in this index case by the finding of normal brain tissue lying in the midst of the blood vessels. Early venous drainage which is an aid to making the diagnosis of AVM's was not demonstrated in this case.

The picture (cross sectional CT or MRI) in large developmental venous anomalies is that of enhancement of the dilated medullary veins which is described as a caput medusa or an inverted umbrella. In dural arterio-venous fistulas, dilated cortical veins which manifest as abnormal enhancing tubular structures or flow voids within the cortical sulci with no true nidus within the brain parenchyma are seen and in Moyamoya disease, there is the presence of tiny flow voids arising from the basal cisterns and extending into the basal ganglia or the thalamus with no true nidus embedded within the brain parenchyma and no dilated vessels(11).

In reporting the presence of evidence of previous haemorrhage (which was not seen in this patient) and the risk of future haemorrhage should be quantified. While the risk of haemorrhage is between $4-6 \%$ per year (7), the risk in this patient was not quantified considering that he already had debilitating symptoms. The report should also include secondary effects of the AVM's which may include gliosis, hydrocephalus, arterial steal amongst others. The index patient had a midline shift and hydrocephalus. It should be noted that AVM's may change in size (9), but no comments can be made on this as this was the first brain scan the patient was having. On this premise also, it may not be possible to say if this was a de novo AVM since there are no previous brain scans available for comparison.

\section{Conclusion}

This case was reported to highlight the fact that though rare, brain AVM's do occur in our environment and healthcare workers may use this as a starting point to expand their knowledge on the subject. The poor health seeking behaviour which is rampant in our environment ${ }^{12}$ remains a source of worry considering that this patient has had two previous episodes of seizures and healthcare was not sought for him.

\section{Conflict of Interest}

Kiridi EK is the proprietor of Silhouette radio-diagnostic consultants were images for this patient were obtained

\section{Consent}

Verbal consent for the use of images for learning purposes was given by the parents of OI on the condition that the images were anonymised.

\section{References}

[1] Adeyinka O, Ibinaiye PO. Brain arteriovenous malformations : Report of a case. Nigerian Journal of Surgical Research. 2005;7(1):216-219.

[2] Neil JA, Li D, Stiefel MF, Hu YC. Symptomatic de novo arteriovenous malformation in an adult: Case report and review of the literature. Surgical Neurology International. 2014;5:148. doi:10.4103/21527806.142796.

[3] Adeniji- Sofoluwe AT, Adeleye AO. Intracerebral arteriovenous malformation: Diagnosis of a case with Computerized Tomography imaging. AJNS.2011;30(1). Available at: http://www.ajns.paans.org/article.php3?id_article=201. Accessed September 23, 2014.

[4] Odeku EL. Intracranial Vascular Anomalies in Nigerians. Journal of the National Medical Association. 1968;60(3):173-180.

[5] Herzig R. Burval S., Viadyka V. Familial occurrence of cerebral arteriovenous malformations in sisters: case report and review of the literature. European Journal of Neurology, 2000; 7(1): 95-100.8.

[6] Stevens J, Leach JL, Abruzzo T, Jones BV. De Novo Cerebral Arteriovenous Malformation : Case Report and Literature Review. Am J Neuroradiol2009:111-112. doi:10.3174/ajnr.A1255.

[7] Sami MT, Bohnstedt BN, Hattab EM, Markham R, Cohen-Gadol AA. Cerebral arteriovenous malformation presenting with polycythemia vera: A case report and literature review. International Journal of Surgery Case Reports.

2013;4(10):813-817. doi:10.1016/j.ijscr.2013.06.019.

[8] Friedlander RM. Clinical practice: arteriovenous malformations of the brain. N Engl J Med 2007;356 (26):2704-2712..

[9] New PFJ, Ojemann RG, Davis KR, Rosen BR, et al. MR and CT of Occult Vascular Malformations of the Brain. AJNR 1986;7:771-779.

[10]Lee BCP, Herzberg L, Zimmerman RD, Deck MDF. MR Imaging of Cerebral Vascular Malformations. AJNR 1985;6:863-870.

[11] Geibpraser S, Pongpech S, Jiarakongmun P, Shroff MM,Armstrong DC, Krings T. Assessment of Brain Arteriovenous Malformations : What Clinicians Need to Know RadioGraphics 2010; 30:483-501

[12] Egbi OG, Okafor UH, Meibodei KE, Kunle-olowu OE, Unuigbe EI. Prevalence of Hypertension in an Urban Population in Bayelsa State, J Med Res Pract. 2013;2(1):11-15. 